\title{
Split-step scheme for photon-pair generation through spontaneous four-wave mixing
}

\author{
Koefoed, Jacob Gade; Christensen, Jesper Bjerge; Rottwitt, Karsten
}

Published in:

2017 Conference on Lasers and Electro-Optics Europe \& European Quantum Electronics Conference

Link to article, DOI:

10.1109/CLEOE-EQEC.2017.8087370

Publication date:

2017

Document Version

Peer reviewed version

Link back to DTU Orbit

Citation (APA):

Koefoed, J. G., Christensen, J. B., \& Rottwitt, K. (2017). Split-step scheme for photon-pair generation through spontaneous four-wave mixing. In 2017 Conference on Lasers and Electro-Optics Europe \& European Quantum Electronics Conference (pp. 1-1). IEEE. https://doi.org/10.1109/CLEOE-EQEC.2017.8087370

\section{General rights}

Copyright and moral rights for the publications made accessible in the public portal are retained by the authors and/or other copyright owners and it is a condition of accessing publications that users recognise and abide by the legal requirements associated with these rights.

- Users may download and print one copy of any publication from the public portal for the purpose of private study or research.

- You may not further distribute the material or use it for any profit-making activity or commercial gain

- You may freely distribute the URL identifying the publication in the public portal 


\title{
Split-Step Scheme for Photon-Pair Generation Through Spontaneous Four-Wave Mixing
}

\author{
Jacob G. Koefoed, Jesper B. Christensen, Karsten Rottwitt \\ Department of Photonics Engineering, Technical University of Denmark, 2800 Kongens Lyngby, Denmark
}

The rapid development of quantum information technology requires the ability to reliably create and distribute single photons [1]. Photon-pair production through spontaneous four-wave mixing (SpFWM) allows heralded single photons to be generated at communication wavelengths and in fiber, compatible with conventional communication systems, with small losses. Creating single photons in desired quantum states require careful design of waveguide structures. This is greatly facilitated by a general numerical approach as presented here. Additionally, such a numerical approach allows detailed analysis of real systems where all relevent effects are included.

In general, the joint temporal amplitude (JTA) of the photon pair, $\mathcal{A}\left(z, t_{\mathrm{s}}, t_{\mathrm{r}}\right)$, where $t_{\mathrm{s}}, t_{\mathrm{r}}$ are the signal and idler arrival times and $z$ is the waveguide position, evolves according to a differential equation of the form [2]

$$
\frac{\partial \mathcal{A}}{\partial z}=(\mathcal{D}+\mathcal{N}) \mathcal{A}+\mathcal{S}, \quad \mathcal{A}(z=0)=0,
$$

where $\mathcal{D}, \mathcal{N}$ and $\mathcal{S}$ are operators representing linear dispersive and lossy, nonlinear phase-modulating (NPM) and spontaneous scattering (SC) effects, respectively. Assuming an instantaneous material response, they take the form

$$
\begin{aligned}
& \tilde{\mathcal{S}}\left(z, \omega_{\mathrm{s}}, \omega_{\mathrm{r}}\right)=\mathrm{i} \sqrt{\gamma_{\mathrm{s}}(z) \gamma_{\mathrm{r}}(z)} \int_{-\infty}^{\infty} \mathrm{d} \omega\left[A_{\mathrm{p}}\left(z, \omega_{\mathrm{s}}+\omega\right) A_{\mathrm{q}}\left(z, \omega_{\mathrm{r}}-\omega\right)+A_{\mathrm{p}}\left(z, \omega_{\mathrm{r}}+\omega\right) A_{\mathrm{q}}\left(z, \omega_{\mathrm{s}}-\omega\right)\right], \\
& \tilde{\mathcal{D}}\left(z, \omega_{\mathrm{s}}, \omega_{\mathrm{r}}\right)=\mathrm{i}\left(\beta_{\mathrm{s}}^{(1)}(z) \omega_{\mathrm{s}}+\frac{1}{2} \beta_{\mathrm{s}}^{(2)}(z) \omega_{\mathrm{s}}^{2}+\beta_{\mathrm{r}}^{(1)}(z) \omega_{\mathrm{r}}+\frac{1}{2} \beta_{\mathrm{r}}^{(2)}(z) \omega_{\mathrm{r}}^{2}\right)-\alpha\left(z, \omega_{\mathrm{s}}\right)-\alpha\left(z, \omega_{i}\right), \\
& \mathcal{N}\left(z, t_{\mathrm{s}}, t_{\mathrm{r}}\right)=2 \mathrm{i}\left[\gamma_{\mathrm{s}}(z)\left(\left|A_{\mathrm{p}}\left(z, t_{\mathrm{s}}\right)\right|^{2}+\left|A_{\mathrm{q}}\left(z, t_{\mathrm{s}}\right)\right|^{2}\right)+\gamma_{\mathrm{r}}(z)\left(\left|A_{\mathrm{p}}\left(z, t_{\mathrm{r}}\right)\right|^{2}+\left|A_{\mathrm{q}}\left(z, t_{\mathrm{r}}\right)\right|^{2}\right)\right],
\end{aligned}
$$

where $\omega_{\mathrm{s}}$ and $\omega_{\mathrm{r}}$ are the signal and idler frequencies, relative to the central frequencies of these fields, $\gamma(z)$ is the nonlinear coefficient, $\alpha(z, \omega)$ is the loss coefficient, $\beta^{(n)}(z)$ is the $n$th order dispersion parameter and tilde denotes the operator in Fourier space. Eq. (1) has exact solutions under each operator individually, in either timeor frequency space. This suggests the use of a split-step algorithm [3]. Analysis of Eq. (1) reveals that a local error of order $\Delta z^{3}$, similarly to the error of a regular symmetrized split-step scheme, can be achieved by applying the steps as follows: (1) Half SC step, half dispersion step. (2) Full NPM step, half dispersion step, full SC step, half dispersion step. (3) Full NPM step, half dispersion step, half SC step. (1) is applied once, (2) is repeated to achieve the desired propagation distance and finally (3) is applied once. Figure 1 shows the numerically calculated JTA and its Fourier transform, the joint spectral amplitude (JSA), where a single Gaussian pump with duration $\tau=200 \mathrm{fs}$ is used and propagated through $30 \mathrm{~cm}$ of fiber using the asymmetric scheme to give pure single photons for use in e.g. linear optical quantum computing [4]. The first case has a near-zero generation rate and no higher-order
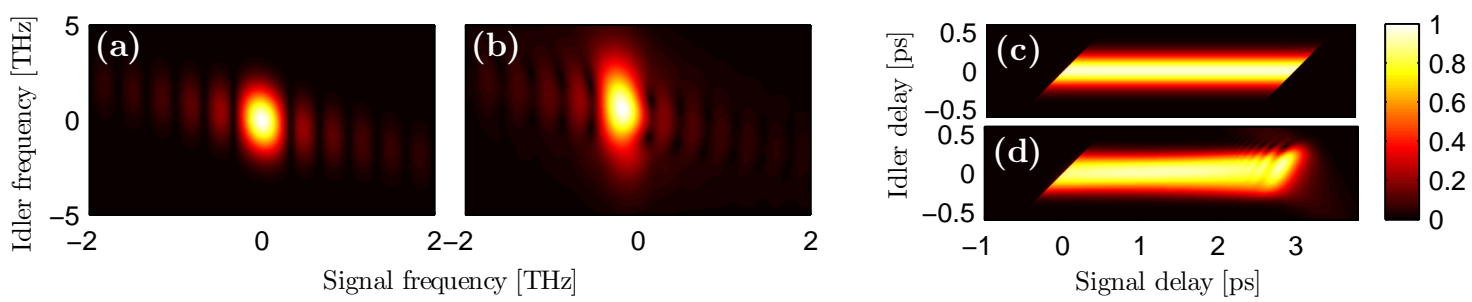

Fig. 1. Absolute value of the JSA with (a) and without (b) NPM and dispersion and the absolute value of the JTA with (c) and without (d) NPM and dispersion.

dispersion while the second case has a generation rate of 0.1 and $\beta_{2}=2.5 \times 10^{-26} \mathrm{~s}^{2} \mathrm{~m}^{-1}$ for all fields. The significant broadening of the JSA from NPM and the distortion of the JTA due to dispersion, even with realistic parameters for a silica fiber, gives a significant reduction in single-photon purity from 0.93 to 0.82 . This illustrates the benefit of a numerical model, which can include effects that are difficult to include in analytical models.

\section{References}

[1] N. Gisin and R. O. B. Thew, Nat. Photon. 1, 165-171 (2007).

[2] J. G. Koefoed, J. B. Christensen and K. Rottwitt, arXiv:1612.04230 (2016).

[3] B. Bell et al., Physical Review A, 92, 5, 053849 (2015).

[4] E. Knill, R. Laflamme, and G. J. Milburn, Nature, 409, 46-52 (2001). 